\title{
COMPARATIVE STUDY OF LEADERSHIP STYLES IN PUBLIC AND PRIVATE SECONDARY SCHOOLS IN IDO LOCAL GOVERNMENT AREA OF IBADAN, OYO STATE
}

\author{
Eunice B. BAKARE ${ }^{1}$ (1) and Afolakemi O. OREDEIN ${ }^{1}$ (1) \\ ${ }^{1}$ Department of Educational Management Faculty of Arts \& Education, Lead City University, Ibadan, Oyo State, Nigeria
}
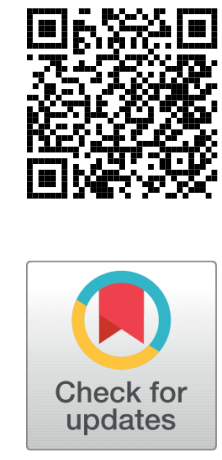

Received 6 May 2021

Accepted 20 May 2021

Published 31 May 2021

Corresponding Author

Eunice B. BAKARE, eunicebakare1

23@gmail.com

DOI $10.29121 /$

granthaalayah.v9.i5.2021.3933

Funding: This research received no specific grant from any funding agency in the public, commercial, or not-for-profit sectors.

Copyright: (C) 2021 The Author(s). This is an open access article distributed under the terms of the Creative Commons Attribution License, which permits unrestricted use, distribution, and reproduction in any medium, provided the original author and source are credited.

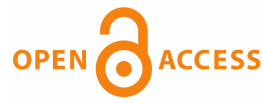

\section{ABSTRACT}

This study compared the leadership styles of principals dominating in both public and private secondary schools in Ido Local Government Area of Ibadan, Oyo State, and also investigated the principals' gender differences. Leadership styles examined include: autocratic, visionary, pacesetting, democratic, coaching, servant, laissez-faire, transformational, transactional, bureaucratic and digital. A descriptive research design was adopted. The population of the study consists of 26 public secondary schools and 97 registered private secondary schools. The total population of teachers in the study were 1194 . Using the Taro Yamane formula, a sample size of 306 respondents were sampled of which questionnaires were administered and 305 questionnaires were retrieved and used for analysis. A self-designed questionnaire that yielded reliability coefficients of $r=0.942,0.911,0.924$ were used for data collection. A research question and two hypotheses were used to guide the study. The findings of the study showed a significant difference in the leadership style adopted by school principals of both school types with mean $=92.5$ and $1149, \mathrm{SD}=9.712$ and 11.634 , while $(t=0.719 ; \mathrm{df}=301, \mathrm{p}<0.05)$. There is also a significant gender difference in the leadership style adopted by principals of both schools with mean $=125.14$ and 120.97, $\mathrm{SD}=14.195$ and 9.318 and $(\mathrm{t}=2.909 ; \mathrm{df}=301 ; \mathrm{p}<0.05)$. The study concluded that though there are significant differences in the leadership styles adopted by the school principals, there are no one best leadership styles. It is therefore recommended that; principals of both school types should blend and adopt styles that best fit the situation at hand. Thus, leadership style should be applied based on contingency.

Keywords: Leadership, Leadership Styles, Public School, Private School, Principal

\section{INTRODUCTION}

The role of a leader (school principal), becomes very imperative as they are the leading bodies initiating positive reforms, ensuring effective learning and educational 
goals while realising national objectives. Leadership could be defined as service to humanity. Alan and S (2017) asserted that leadership is more than displaying authority and being recognized by others as having power. It is about having the capacity to overcome obstacles and helping the followers see through into the future. It is helping and guiding others through to develop the right attitude not only to maximize the organization goal but also maximize their aspirations in life. Lindblom (2018) viewed leadership in education as doing all necessary to support both students and teachers, ensuring teachers have all they need to do their job well. Effective leadership is all about learning, developing and adapting skills, and practices. it requires a conscientious effort in transmitting knowledge to the followers in such a manner that gets them actively execute the goals and objectives set by the leader Ward (2020) opined. In other words, the leader motivates and get others to work by having the required leadership skills and charisma that makes followership desirable. Leadership can also be linked to performance which may not solely be about profit.

People have etched their name in gold in history, having no previous leadership experience, have stepped to the front in critical situations and swayed others to follow their proposed course of action Ward (2020). They owned traits and qualities that aided them to step into roles of leadership. Steve Jobs is a classic example of someone who learned to lead despite not being born a natural leader. In the opinion of Ward (2020) the greatest leaders to ever live not only succeed at helping their team succeed and conquer new-fangled and lead the marketplace but also profoundly care for people and understand the honour of being a leader. Leaders possess the capacity of influencing the everyday life of their follower. This ranges from the simple smile and greetings accorded to their followers or even calling and remembering their names. It could also mean being obsessive about helping employees be their very best while pursuing all of their dreams and desire, even their professional goals. Leaders could also encourage their employees to develop and mature in character and their profession thus living them a better person than he, the leader meant them.

More so, one needs several qualities to become a fantastic leader. However, a good leader should be desirous about making the best use and advance the abilities and giftings of their employees. A leader skilled in transforming individual employees can easily transform the organization or team as well. As it is needful for athletes to regularly exercise and continually labour to improve their game, it is also expedient for leaders to possess the same attitude or technique of finding ways to become more competent in leading and inspiring employees to do their job well, giving all that it takes to discover and help them develop their hidden potentials thereby becoming all they ought to be. Understanding true leadership will not only transform the organization but also the leader as well. Thus, the greatness of a leader is measured by the achievements of his followers. This is the ultimate test of effectiveness Dasakal (2016).

The procedure or manner in which a leader leads (the school principal) is termed, leadership style. This includes his personality, the way he or she relates with his fol- 
lowers, the need for the work in question and the organizational culture in which the school operates. This study examined eleven leadership styles: autocratic, visionary, pacesetting, democratic, coaching, servant, laissez-faire, transactional, transformational, bureaucratic, and digital.

The autocratic style of leadership entails the leader believes he or she knows it all and does not need any input, suggestions or contribution from other members of the team. The phrase commonly used for autocratic leadership is "Do as I say" asserted by Kruse (2019). Leadership here is more of a command and control, which is typical of the leadership style of the past and cannot survive in today's world and talent. This type of leadership creates a climate of fear with little or no room for dialogue. On the other hand, this leadership style can still be appropriate in certain structures where crucial and quick decisions had to be made on the spot and about the situation, or where the leader is dealing with a new employee and had little or no time for them to gain mastery with their new role. An autocratic leader focuses on result and efficiency Kruse (2019).

The visionary style of leadership requires leaders to lead the way while setting examples motivating and stimulating employees to do the same. A phrase commonly indicative of this leadership style is "Follow me". A visionary leader is a confident leader who 'lifts the flag' Kruse (2019) for people in a climate of uncertainties. They help their employees understand the goals and objectives of the company and also intimate them with the company's plan and their future responsibilities. Distinct from autocratic leaders, visionary leaders spend their time amplifying thoughts. They do not just give the command, but allow their employees to make contributions on how to achieve the common goal of the organization. This leadership style support organization that is small and fast-growing or larger organizations that are undergoing corporate reforming.

The pacesetting leadership style is a style of leadership where the leader sets the standard high. The phrase most commonly used by the leader is 'Do as I do' (Kruse, 2019) Kruse (2019). This leader raises the standard high and encourages their followers or employees to work hard and fast to attain the organizational goal. This leadership style is effective in getting the work done and it is result-oriented. Though the pacesetting leadership style is highly motivational and supportive in a fast-paced environment where employees need motivation, it is not the best style for employees who need to be mentored and given feedback. This style may also harm employees in that they may become tense working in the long run.

The democratic style of leadership gives power to the people in a setting or institution full of competent employees. They make room for change and adaptation, relies on input from their team and also considers feedback. Democratic leaders are often people-oriented and ensure everyone takes ownership for decision making and success. They encourage oneness, collaboration and cooperation from employees and engender trust. This leadership style also creates room for creativity while helping employees grow and develop their skills and ability. Since this leadership style fos- 
ters participation and is discussion-driven, it can be an excellent style for an organization that is focused on creativity and innovation such as the educational and technological industry.

The coaching style of leadership view people as well as talents that needs to be developed Kruse (2019). Thus, leaders who coach seeks to unlock peoples 'hidden abilities and potential. They believe everyone has something to offer and are receptive to accommodating people. Also, they direct and help people discover and connect with their abilities to attain all they are capable of becoming. The coach leadership style is one of the valuable styles for both managers and employees alike. Though it is often under-initiated because it is more time-intensive as compared to other types of leadership. If adopted by any organization, it stands the test of time.

The servant style of leadership believes people come first Kruse (2019). Hence, leaders get close and personal with their team members. A servant leader pays attention to support their employee's emotional needs. They open up the link that connects them to their team members. Furthermore, this style encourages oneness and collaboration among employees and it is a commonly used style in non-profit organizations.

The laissez-faire style of leadership can be viewed as the reverse of the autocratic style. This style focuses more on entrusting numerous tasks to employees with little or no supervision of the leader. Laissez-faire leaders often have more time for their projects than spend time managing their employees. This type of leadership can be adopted by managers whose employees are vastly skilled, well proficient and need little or no supervision. On the other hand, this may lead to a decrease in productivity if employees are not sure of their leader's expectations or if some employees need supervision and inspiration as well as restrictions to work well.

Dasakal (2016) stressed that the transactional style of leadership requires leaders to offer an exchange by rewarding good performances while punishing bad practice, this leadership style focuses on group organization, establishing a clear chain of command and responsibility for each employee. They also use incentive programs to motivate workers. This leadership style is good for establishments with high explicit goals such as in sales and revenue, but it is not the best style for driving creativity.

Also, Dasakal (2016) opined that the transformational style of leadership motivates team members with a common vision of the future, and also communicates well with employees. These leaders are proactive, adjust easily, self-aware, empathetic, authentic and humble. They inspire their team members to expect the very best from them. They are held accountable for their actions, set clear goals and have good conflict resolution skills which lead to high productivity and engagement. They are also able to change and adapt other styles of leading as the situation demand.

The bureaucratic leadership styles emphasise static rules and duties where members of a team are expected to follow the set rules and procedures written out for them by their leader and there is rarely any room for teamwork, innovation and ingenuity. Leaders here lead by following established rules, making sure the organiza- 
tion structure is being followed dutifully. More so, a bureaucratic leader is well organized, consistent, detail-oriented and task-focused, often dealing with routine jobs. This form of leadership style is active in well-regulated industries or departments, such as finance, healthcare and government establishment Mooney (2018). Bureaucratic style of leadership engages in a highly official set of processes, procedures and structures. This sometimes creates a bottleneck and delays in the implementation of activities within the organization.

The digital style of leadership is the advanced form of transformational leadership. It uses technology including digital device, service and resources to advance communication, organize work and lives, and create new ways of doing old things well. Digital leaders understand technology as much as they understand money Hordos (2018). They are curious about their work, always looking for the best and new way to get the organizational task accomplished; they also encourage their team members to do the same. They are often open to learning, understand the need of the time and work to meet it. Hordos (2018) conceived that a digital leader makes their work appealing, relevant, fundable accessible, and cheap to develop and deliver.

All the fore mentioned leadership styles can be influenced by many factors such as personality trait, belief system, organizational culture, employee diversity, financial security and technological skills.

Personality trait influencing leaders are upbringing, education, self-worth, religious view, gender, introversion, extroversion and circumstances of life. Also, the way the leaders' handle what life throws at them affects their conduct and roles Hordos (2018). Leaders' personality traits cannot be ignored. Aligning the leaders' elementary nature with a specific method of leadership is most often successful. This is because the leader will feel comfortable being his or herself. In a situation where the leader keeps a charming disposition that draws people to him or her, he will likely adopt a transformational style that develops faithful staff wanting to satisfy their leader. Also, a leader that is most relaxed with ensuring that set rules and decorum is followed will likely adopt the autocratic style in which employees are trained to carry out their duty's instinct according to the stated rules and regulations.

Also, Hordos (2018) opined that the belief system or professional ethics of a leader can also influence his method of leadership. When a leader believes in collaboration as the most effective style to work, he or she will adopt the democratic style in his leadership. This style requires the leader to work hand in hand with his employees to get the work done. This fosters team spirit and cooperation. But leaders that see employees has been well able to be delegated task to do well as transformational leaders. This type of leaders determines what employees need to work on and guide them to get the work done. Thereby motivating them to be committed to realizing the goals and objectives of the organization.

The organization Culture or the nature of school culture can influence a leader's leadership style. If a culture of well-trained and motivated employees exists in a school, the leader may likely adopt the Lassez-faire style. In this method, the leader 
believes his or her employees are capable of handling their work without much supervision. Thus, the leader only inspires his employees without any unnecessary interference from the leader. More so, Hordos (2018) stated that some organizations perceive creativity as one of the determining factors to the success of their organization. The organizational culture of leading and helping employees discover and unlock their God given gifts and abilities thereby stimulating them to do what they naturally think they are not capable of doing requires a creative leader who will motivate and spur his employees to be creative and innovative in their way of thinking. This is a typical coaching leadership style.

Employee diversity, leaders must be diverse in their approach to dealing with their staff or employees as there exists a likely hood of them employing employees of diverse cultures, races, genders and age groups Mooney (2018). The style of leadership most suitable with the diverse set of employees is the participating or democratic style in which leaders work meticulously with employees, helping them succeed. Servant leadership is another effective style that works best for employees of unlike upbringings. Here, the leader dedicates his efforts to meeting the employee needs so they can mature as workers and influence other employees and their students in doing the same.

Financial Security is another factor that can influence a leaders' style of leading. Employers who offer competitive pay-checks to their employees from the beginning have set the employees motivated. A leader that is well motivated as a result of good pay which brings about financial security will be willing to adopt all best practices in leadership styles to ensure that the organization is set on a pedestrian path of success. This simply implies that, when a leader does not have financial stress he or she knows that his or her needs are met, will be willing to give all that it takes to ensure that the organizational goals and objectives are achieved in any way suitable to his or her leadership style. On the other hand, a leader with financial insecurity will be psychologically unfit to execute educational goals and objectives. This is because there is an underlined burden and pressure that becloud his mind, thus will not be able to lead effectively irrespective of the leadership style he adopts. It has been observed that most public school leaders are not always found at their duty post as they pursue other sources of financial security at the expense of the discharge of their duty. And this has eroded the performance of the leaders and students.

Technology Skills of a leader may influence a leaders' style of leading in speed, accuracy and in getting the work done effectively. The 21st-century schools demand higher-order learning skills for students and teachers alike and school leaders (principals) are expected to facilitate these changes Suarez (2012). Leaders that are very proficient in the use of technology will also produce proficient teachers and students which in turn will lead to high productivity and high academic performance. Topperforming leaders understand and make use of technology to automate repetitive tasks, fast track their work and raise expectations. Furthermore, the role of educational leaders in this 21 st-century has changed because many companies have trans- 
formed their educational system and schools to better prepare learners for today's world of economic globalization and increase the mobility of people. The technological skills of 21st-century leaders, therefore, cannot be overemphasized because it makes room for innovation, increases problem-solving skills, increase productivity and efficiency.

A leader's gender at times may also influence his or her leadership role. Gender could be defined as the role a male or a female plays in society. It is not the same as sex. Sex, therefore, is the biological differences between male and female. Sometimes, a person genetically assigned sex or being a male or a female does not correspond with their gender identity. Thus, these individuals may refer themselves to be transgender or non-binary. In Africa, a patriarchal society exists, where men are assumed to be favourably fit in matters of leadership and decision making. While women tend to be marginalized in every area of leadership. Gender difference is a global phenomenon that cuts across culture, behaviour, beliefs, socialization and upbringing. Recent studies and research have shown that female leaders (principals) are more task and people-oriented than their male counterparts.

It has been observed from existing studies that there are no better leadership styles than the other. The fact remains that leadership styles have their relevance in a leader's way of leading people. A prudent and effective leader knows how to switch between styles of leadership as the circumstances demands. Thus, leadership

styles are a continuum. Hassan (2018) revealed in a study that shows the impact of leadership styles on organizational performance that organizational performance is associated with leadership styles having both negative and positive impact on performance. The success of any organization, therefore, depends on its leadership as they are the force that initiates an action in people. This study compared the various leadership styles in Public and Private secondary schools in Ido local government area during the COVID-19 pandemic.

\section{STATEMENT OF THE PROBLEM}

It has been generally observed over the years that the success of any organizational system, be it public or private depends largely on the leadership. Many organizations had gone into extinction due to the operation of poor leadership style in place. The current problem the world is facing (COVID-19 pandemic), has left most developing countries like Nigeria in a state that may be difficult to recover from shortly, especially, in the area of education if some drastic measures are not put in place. The reality now is that schools not led by a digital/ transformational leader may likely be on the verge of losing pupils/ students while those that are technologically inclined may be gaining more grounds and be more effective. Some research work has been done to compare the leadership styles of principals in Onitsha and the effect it had on the effectiveness on teachers and students' academic excellence. Also, much has been said on how principals' behaviour, administrative skills and work environment 
among others, affect the leadership roles. However, the leadership styles of school principals of both Public and Private Secondary Schools in the Ido Local Government Area of Ibadan, Oyo State has not been researched at all. To this end, this study will compare the leadership styles of school principals of both Public and Private Secondary Schools in the Ido Local Government Area of Ibadan, Oyo state.

\section{RESEARCH QUESTION}

What type of leadership styles dominate in both Public and Private Secondary Schools in the Ido Local Government area of Ibadan, Oyo State?

\section{HYPOTHESES}

The following hypotheses will be tested at a 0.05 level of significance

1. There will be no significant difference in leadership styles dominating in both Public and Private secondary schools in the Ido Local Government area of Ibadan, Oyo State.

2. There will be no significant gender difference in the leadership style adopted by principals of both Public and Private secondary schools.

\section{METHODOLOGY}

The research design was a descriptive design of the survey type. The population of the study consists of (26) Public and (97) registered Private secondary schools in Ido local government area. The population of teachers in Public schools were 244 while that of private schools was 970, summing up to 1194 teachers in both schools. The sampling technique used for sample selection is the Taro Yamane formula with a 95\% confidence level. A sample size of at least 300 respondents was selected.

The research instrument used for data collection was a questionnaire which was divided into three sections: A, B, C. Section A measures the demographic data of the respondents, section $B$ contain prevalent items that measure leadership styles and section $\mathrm{C}$ contains parameters that measure the differences in the leadership styles in the selected secondary schools. The instrument was given face and content validation. A pilot study was carried out to validate the instrument and the reliability of the instrument gave a coefficient value of $r=0.943,0.911,0.923$ for all three sections respectively. Data collected were analysed using frequency, percentage and graph for biodata, while frequency, mean scores, weighted means, standard deviation and percentage were used in analysing the research question and a t-test was also used to test the hypothesis at 0.05 level of significance. 


\section{RESULTS}

Research question: What type of leadership styles dominate in both Public and Private Secondary Schools in the Ido local government area of Ibadan, Oyo State?

Table 1 Prevalent Leadership Style in Public and Private Secondary Schools in Ido Local Government Area of Oyo State

\begin{tabular}{lll} 
Leadership Styles & Public School & Private School \\
Coaching & $7(9.7 \%)$ & $13(5.6 \%)$ \\
Visionary & $4(5.6 \%)$ & $11(4.7 \%)$ \\
Servant & $2(2.8 \%)$ & $5(2.2 \%)$ \\
Autocratic & $6(8.3 \%)$ & $26(11.2 \%)$ \\
Laissez-faire & $5(6.9 \%)$ & $9(3.9 \%)$ \\
Democratic & $21(29.3 \%)$ & $14(6.0 \%)$ \\
Pace setting & $5(6.9 \%)$ & $19(8.2 \%)$ \\
Transformational & $7(9.7 \%)$ & $69(29.6 \%)$ \\
Transactional & $5(6.9 \%)$ & $16(6.8 \%)$ \\
Bureaucratic & $8(11.1 \%)$ & $30(12.8 \%)$ \\
Digital & $2(2.8 \%)$ & $21(9.0 \%)$ \\
Total & $72(100 \%)$ & $233(100 \%)$ \\
\hline
\end{tabular}

Table 1 presents the prevalent leadership style in public and private secondary schools in the Ido local government area of Oyo State. It was revealed that in public secondary schools, democratic leadership style was the prevalent style among school principals with $29.3 \%$ while in private secondary schools in the Ido local government area of Oyo state, a transformational style emerged as the prevalent leadership style among school principals with $29.6 \%$.

\section{Hypotheses Testing}

$\mathbf{H}_{01}$ : There will be no significant difference in leadership styles dominating in both public and private secondary schools in the Ido local government area of Oyo State.

Table 2 Summary of T-Test Table Showing Difference in Leadership Styles Dominating in Both Public and Private Secondary Schools

\begin{tabular}{cccccccc}
\hline Variable & N & Mean & SD & t & Df & Sig & Remarks \\
\hline School Type: Public & 72 & 92.51 & 9.712 & & & & \\
Private & 233 & 119.49 & 11.634 & & & & \\
\hline Leadership Styles & 305 & 121.34 & 12.217 & & & & \\
\hline
\end{tabular}

Not Significant at 0.05 level of significance

Table 2 shows the t-test table of analysis of hypothesis one formulated on difference in leadership styles dominating in both public and private secondary schools in Ido local government area of Oyo State. The table revealed that there is a significant difference in leadership styles dominating in public and private secondary schools $(t=0.719 ; \mathrm{df}=301 ; \mathrm{P}<0.05)$, then, the hypothesis is rejected at 0.05 level of sig- 
nificance. This implies that there is significant difference in leadership styles dominating in public and private secondary schools in the Ido local government area of Oyo State. The leadership styles dominating in private secondary schools is higher than public secondary schools, this is revealed in the mean values: public (92.51), private (119.49). The standard deviations of public and private secondary schools were given as 9.712 and 11.634 respectively. Mean value for leadership style was given as 121.34 while the standard deviation was 12.217 .

$\mathbf{H}_{02}$ : There will be no significant gender difference in the leadership styles adopted by principals of both public and private secondary schools in Ido the local government area of Oyo State.

Table 3 Summary of T-Test Table Showing Gender Difference in Leadership Styles adopted by Principals of both Public and Private Secondary Schools.

\begin{tabular}{cccccccc}
\hline Variable & N & Mean & SD & t & Df & Sig & Remark \\
Gender: Male & 137 & 125.14 & 14.195 & & & & \\
\hline Female & 168 & 120.97 & 9.318 & 2.909 & 301 & 0.014 & Sig. \\
\hline Principals' Leadership Styles & 305 & 122.84 & 12.394 & & & & \\
\hline
\end{tabular}

Not Significant at 0.05 level of significance

Results of hypothesis two formulated on gender difference in the leadership styles adopted by principals of both public and private secondary schools in Ido the local government area of Oyo State is presented in table 4.9. The table revealed that there is significant difference in leadership styles adopted by principals of both public and private secondary schools $(\mathrm{t}=2.909 ; \mathrm{df}=301 ; \mathrm{P}<0.05)$, then, the hypothesis is rejected at 0.05 level of significance. This implies that there is significant gender difference in principals' leadership styles of both public and private secondary schools in Ido the local government area of Oyo State. Leadership styles adopted by male principals are more effective than that of female principals, this is revealed in the mean values of male and female which are given as 125.14 and 120.97 respectively. The standard deviation of male and female principals was given as 14.195 and 9.318 respectively. Mean value for principal leadership styles was given as 122.84 while the standard deviation was 12.394

\section{DISCUSSION OF FINDINGS}

For the research question, analysis of the study conducted revealed that the leadership style dominating in Public Secondary Schools are the democratic style while that of the Private Secondary schools are the Transformational style. This result collaborates with the study on impact of leadership styles on organizational performance Hassan (2018). The study shows that transformational and democratic leadership styles are commonly used styles in both public and private secondary schools in Nigeria. More so, the study on progressive education and development also agreed with this assertion Ogbiji (2018). This therefore follows that, principals of private 
secondary schools in Ido the Local Government Area of Ibadan are innovative, more creative, proactive to change, inspire team members, achieve higher performance and also place value on employees and their work. This is not surprising that the private secondary schools were able to adapt and strive during the lock down, ensuring that teaching and learning activities are not much affected and students are continuously engaged all through the period of the lock down. Where teaching and learning activities in the public secondary schools were greatly affected by the lock down.

The following hypotheses were tested at a 0.05 percent level of significance:

For hypothesis one, the analysis conducted revealed that there are significant differences in leadership styles dominating in both Public and Private Secondary Schools in Ido Local Government Area of Ibadan, Oyo State. This is clearly shown in table 4.7 with 21 respondents out of 72 from public schools choosing the democratic style of leadership at $29.3 \%$ which is the highest percentage for public schools. Also, the same table result shows that 69 out of 233 respondents voted for transformational style in private secondary schools at $29.6 \%$ which is the highest percentage for private schools. This result agrees with the study on comparative analysis of administrative leadership styles of principals in public and private schools Oriade local government area, Osun State which indicate a significant difference in the leadership style of principals of both Public and Private Secondary School Onongha (2018). However, this result does not agree with the $\mathrm{H}_{1}$ raised. Hence, the hypothesis is rejected at a 0.05 level of significance and the alternative is accepted.

For hypothesis two, the result of the analysis clearly shows a significant gender difference in leadership styles adopted by both male and female principals of both Public and Private Secondary Schools. From the table, the number of male principals were 137 , with a mean value of 125.14 and a standard deviation of 14.195 . While the number of the female principals was 168, with a mean value of 120.97 and a standard deviation of 9.318. This indicates that the male principals are more effective and more preferred than the female principals. This result, collaborates with a study of principal leadership style performance and principal effectiveness in Dubai schools and exploration of the impact of principal leadership behaviour on school culture Onongha (2018), Ibrahim and Al-Taneiji (2012), Numkanisorm (n.d.).

\section{CONCLUSION}

The findings of the study revealed that the leadership styles adopted by principals of both Public and Private Secondary Schools in the Ido local government area of Ibadan, Oyo State differs, hence there are significant differences in leadership styles adopted by both school types. On the other hand, considering the nearest percentage difference closer to the prevalent leadership styles adopted by both public and private secondary school principals, this suggests that in spite of their differences in leadership styles, both school principals tend to share the bureaucratic leadership style in common. This inferred that, there are no best leadership styles and that prin- 
cipals of both public and private secondary schools should adopt the best style that suits the situation at hand or better still blend styles to boost their job performance.

\section{RECOMMENDATIONS}

Based on the findings of the study, it is therefore recommended that:

1. principals in both public and private secondary schools in Ido local government area of Ibadan, Oyo State should adopt the best leadership style that best fit the situation at hand and that leadership style should be applied based on the prevailing contingency.

2. both public and private secondary school principals should not stick to a specific leadership style.

\section{REFERENCES}

Alan, \& S. (2017). A Study Of Leadership Styles By Principals And Academic Coordinator In One Of The Private Schools In GILGIT Baltistan, Parkistan; Academic Research International . A Study Of Leadership Styles By Principals And Academic Coordinator In One Of The Private Schools In GILGIT Baltistan, Parkistan.

Dasakal, L. (2016). President And Ceo, Lead From Within @ LOLLY DASKAL. 100 Answers To Questions: What Is Leadership? President And Ceo, Lead From Within @ LOLLY DASKAL.

Hassan, I. A. (2018). Impact Of Leadership Styles On Organizational Performance. Journal of Human Resources Management Research. Retrieved from Http.//IbizaPublishing.Com/ Articles/Jhrmr/2018/687849/

Hordos, L. (2018). Factors Influencing Leadership Style Bizfluent., 8145993-8145993. Retrieved from Http://Bizfluent.Com>Info_8145993

Ibrahim, A., \& Al-Taneiji, S. (2012). Principal leadership style, school performance, and principal effectiveness in Dubai schools. International Journal of Research Studies in Education, 2(1). Retrieved from https://dx.doi.org/10.5861/ijrse.2012.86 10.5861/ijrse .2012 .86

Kruse, K. (2019). What Is Leadership? CEO Of Lead X And Author Of Great Leaders Have No Rules. Www.Thebalancesmb.Com. Small Business Resources.

Lindblom, K. (2018). What Does Leadership In Education Mean National Council Of Teachers Of English (NCTE). Org > Blog.

Mooney, L. (2018). Factors Influencing Leadership Style. Factors Influencing Leadership Style. Retrieved from Http://Yourbuisness.Azcentral.Com

Numkanisorm, N. P. (n.d.). Exploration Of The Impact Of The Principal Leadership Behaviour On School Culture. Phd. Faculty Of Education. School Of Educational Leadership. Australian Catholic University.

Ogbiji, J. E. (2018). A Comparative Study of the Administrative Effectiveness of Principals of Public and Private Secondary School in Cross River State, Nigeria (Vol. 7). Human Resources Management Academic Research Society (HRMARS). Retrieved from https://dx.doi .org/10.6007/ijarped/v7-i4/5335 10.6007/ijarped/v7-i4/5335

Onongha, G. I. (2018). Comparative Analysis Of Administrative Leadership Styles Of Principals In Public And Private Schools In Oriade Local Government Area. Educational Journal of The University Of Patras UNESCO Chair, 5(1), 2241-9152. 
Robert, K. G. (2021). Greenleaf Centre For Servant Leadership. What Is Servant Leadership?_GreenleafCentre For Servant Leadership. Retrieved from Https://Www.Greenleaf .Org $>$ What_Is_

Sahel, W. Z. (2020). International Commission On The Futures Of Education. Educational Post-COVID-19: Nine Ideas For Public Action Paris UNESCO. Www.UNESO.ORG.

Suarez, L. M. (2012). Influence Of Technology On The Leadership. In Influence Of Technology On The Leadership of 21st-Century Career And Technical Education Administrators. The Graduate School Of Education Of Fordham University. New York.

Ward, S. (2020). What Is Leadership? What Is Leadership? Available Online. Retrieved from Https://Www.Thebalancesmb.Com/Leadership_Definition_2948275 